\title{
Rhodium(I)-Catalyzed [4+2]-Cycloaddition Route to 1,2-Dihydropyridines
}

Synthesis of

Heterocycles

Key words

bridged bicycles

C-H activation

dihydropyridines

piperidines

rhodium catalysis
Significance: Piperidine heterocycles are abundant in numerous pharmaceuticals such as oxycotin, plavix, ritalin, and tofacintinib. The piperidine ring can contain multiple stereocenters, quaternary carbons, or be highly substituted. One method to prepare chiral substituted piperidines is the asymmetric hydrogenation of pyridine or tetrahydropyridine precursors; therefore, a robust, scalable route to a diverse range of substituted pyridines or tetrahydropyridines would be of synthetic value to the pharmaceutical industry. The known Diels-Alder approach to substituted pyridines is compromised by significant electronic and steric constraints (J. A. Varela, C. Saá Chem. Rev. 2003, 103, 3787; D. L. Boger Chem. Rev. 1986, 86, 781; A. Saito et al. Tetrahedron Lett. 2007, 48, 6852).

SYNFACTS Contributors: Victor Snieckus, Brandon P. Schuff (Pfizer) Synfacts 2015, 11(1), 0015 Published online: 15.12.2014 Dol: 10.1055/s-0034-1379737; Reg-No.: V15914SF
Comment: In the presented methodology, a broad scope of 1,2-dihydropyridines was prepared through a rhodium(I)-catalyzed $\mathrm{C}-\mathrm{H}$ activation-alkenylation-electrocyclization sequence of reactions. Treatment with an electrophile under kinetic or thermodynamic control conditions afforded the corresponding iminiums, which then were treated with nucleophiles to afford the desired tetrahydropyridines with high diastereoselectivity. The 1,2-dihydropyridine intermediates were also shown to react in [3+2] or [4+2] cycloaddition modes to afford bridged bicyclic isoquinuclidines and tropane cores. The catalyst loading was low $(<1 \%)$, conditions were robust (air-stable), and the tetrahydropyridines were prepared on scale (>100 $\mathrm{mmol}$ ) in good yield. 